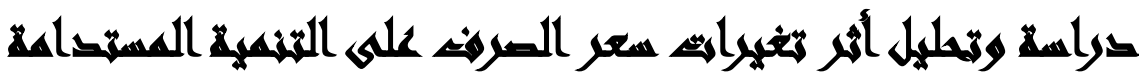

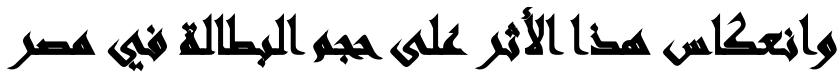

[19]

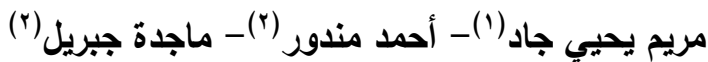

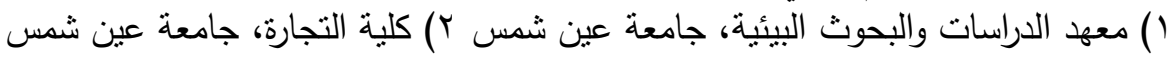

\section{المهرخلص}

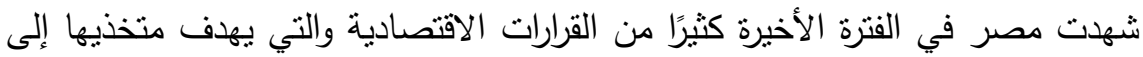

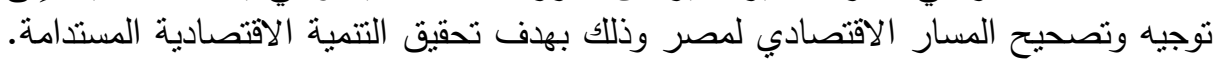

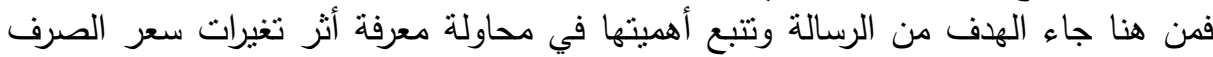

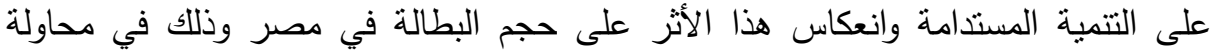
للقضاء على البطالة في مصر والمحافظة على الثراءلى الثروة البشرية وتتميتها كأحد أهم الأبعاد

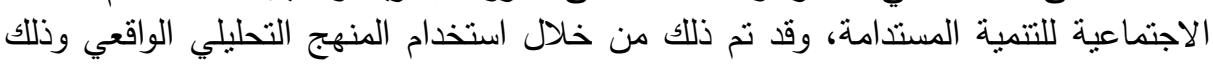

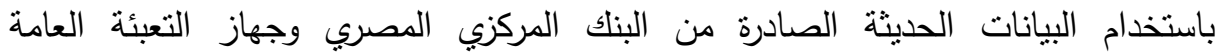
والإحصاء والتي أسفرت عن الأتى. التئ. إن التغيرات التى حدثت لسعر الصنى الصرف كان لها أثر إيجابى على حجم الأحتباطيات

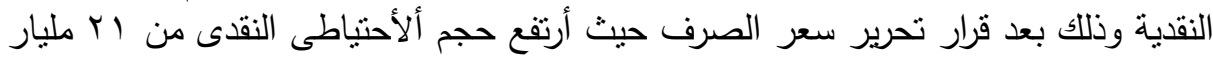

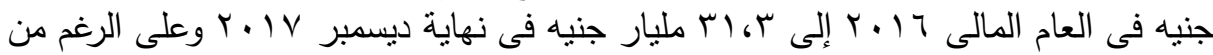
ألأثز الذى يبدو إيجابيا إلا أن يبقى مصدر هذه الزيادة في التى حجم الأحتباطيات مصدرها

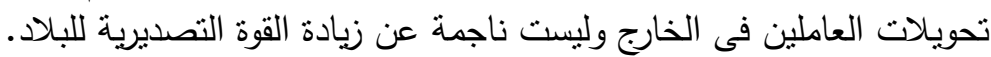

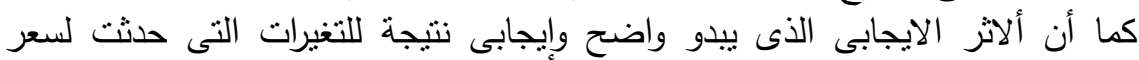

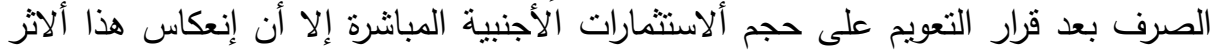

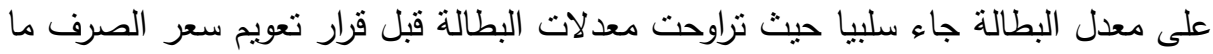

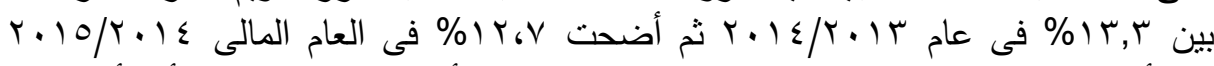

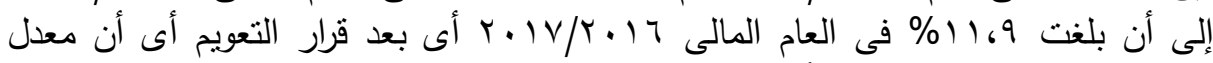
البطالة مازال فى الحدود الغير أمنه والمقبوله عالميات الماليا

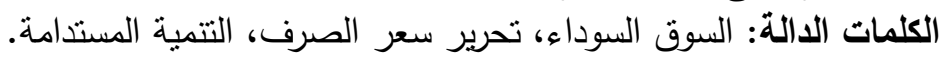




\section{المهمبهد}

لقد شهر العالم الكثير من الأزمات الاقتصادية النقدية في القرن الماضي، وعانت كافة

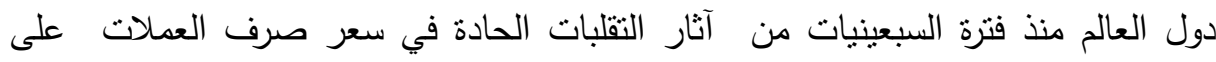

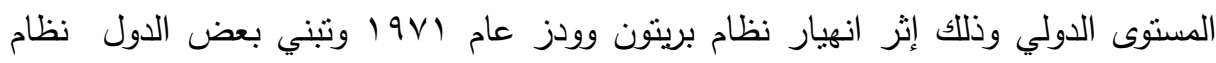

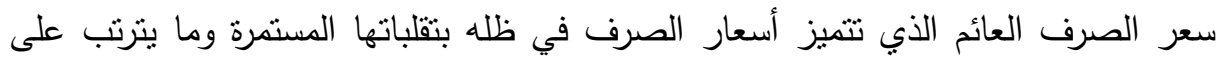
ذلك من آثار سلبية على الأقتصاد بالنسبة لكافة الدول. إن معظم دول العالم الثالث عرفت

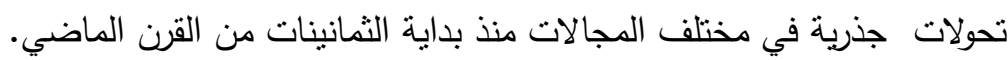

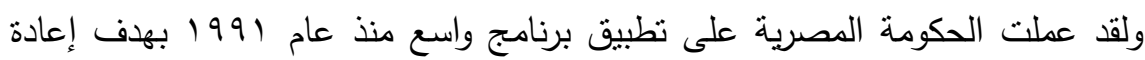

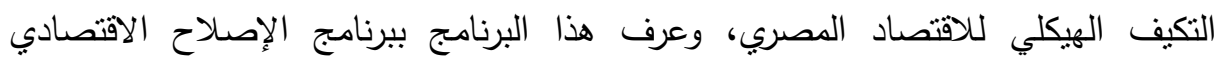

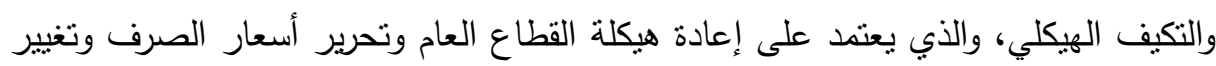
سياسات الاستثمار والتجارة الخارجية والسياسة النقدية.

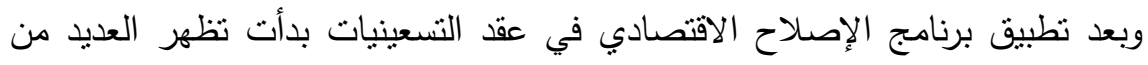

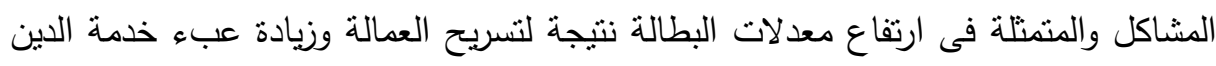
العام الداخلى والخارجى كما ظهرت مشاكل أخرى في بداية القرن الواحد والعشرين والمتمثلة في أحداث 1/ سبتمبر وغيرها من الأحداث والتي عانت من آثارها كثثر من الدول النامية

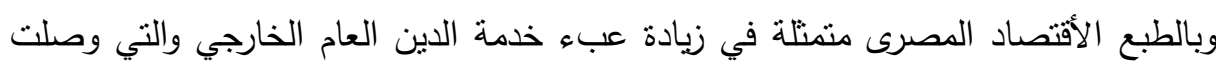

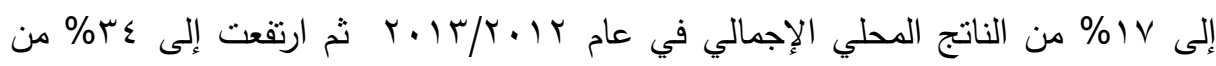

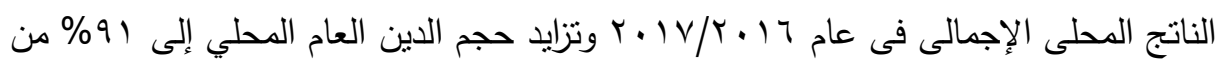

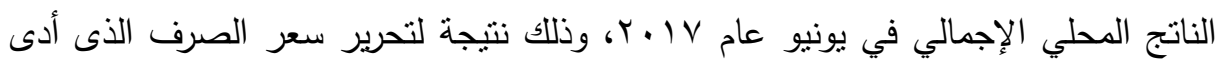
بدوره لانخفاض قيمة الجنيه ولتراجع الاحتياطيات الدولية من العملات الأجنبية لتصل إلى إلى

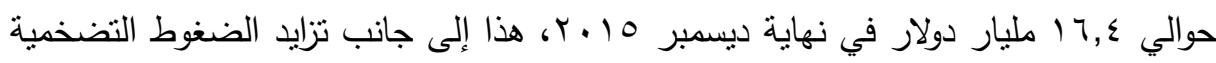

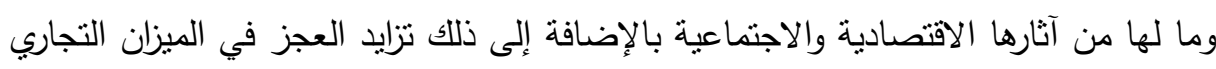

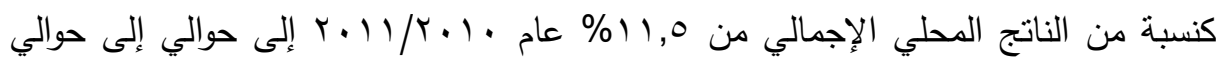

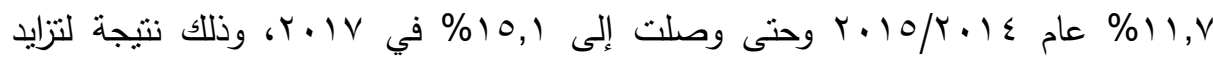
الواردات وقلة حجم الصادرات، وبالتبعية قلة حجم الإنتاج، وبالتالي تخفيض وهن واهريح العمالة

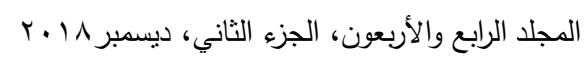


وارتفاع معدل البطالة حيث وصلت نسبة الواردات إلى 9 1\% عام ؛ ( • 10/ • ب وهي نسبة

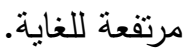

كما شهدت مصر في الفترة الأخيرة كثيرًا من القرارات الاقتصادية والتي يهدف متخذيها إلى توجيه وتصحيح المسار الاقتصادي لمصر وذلك بهدف تحقيق التتمية الاقتصادية

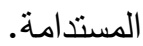
وقد كانت من أهم القرارات التي نم اتخاذها في القريب هو قرار تحرير سعر الصرف أو

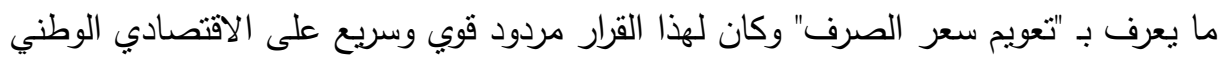
وعلى التنمية المستدامة حيث يتمثل هذا المردود في حدوث كثير من التغيرات في أسعار

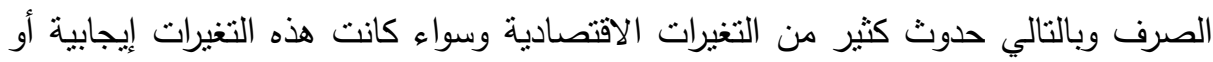
سلبية فأن هذه التغيرات كان لها عظيم الأثر على الوضع الاقتصادي وعلى تحقيق التتمية

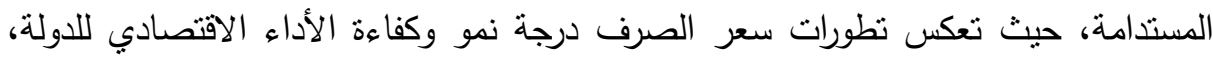
ونتيجة تحرير سوق الصرف في مصر تبعا للسياسات البنك المركزي المصري وتحسن أداء

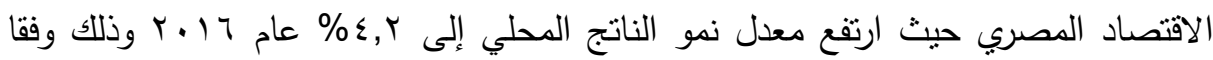

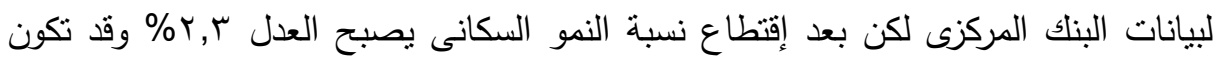

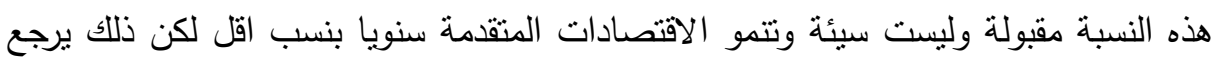

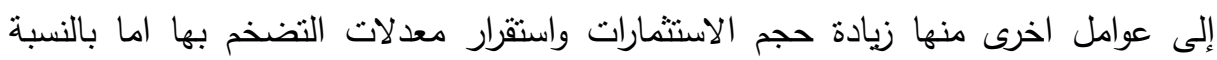

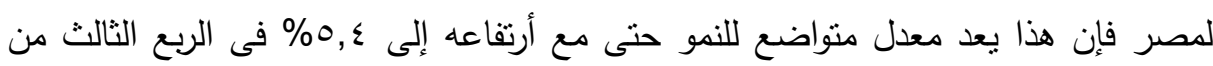

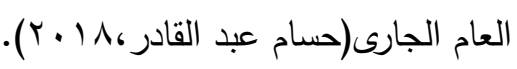
فمن هنا جاء الهدف من الرسالة وتتبع أهميتها في محاولة معرفة أثز تغيرات سعر

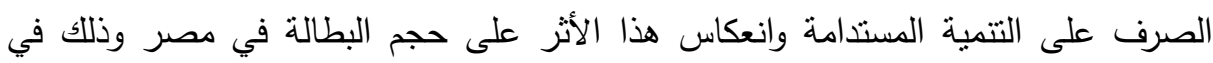

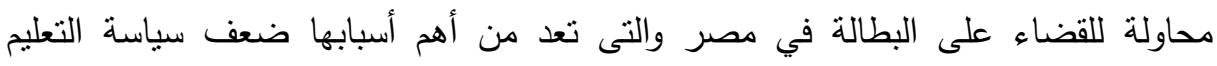
والتدريب كأحد أهم الأبعاد الاجتماعية للتتمية المستدامة، وذلك للحفاظ على الثروة البشرية وقد تم ذلك من خلال استخدام المنهج التحليلي الواقعي وذلك باستخدام البيانات الحديثة الصادرة من البنك المركزي المصري وجهاز التعبئة العامة والإحصاء والتي أسفرت عن أنه نم القضاء

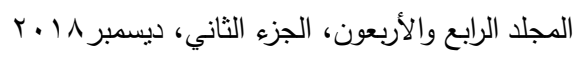


على الأسواق الموازية "السوق السوداء" مع ارتفاع حجم الاحتياطي النقدي إلى ؟, اس مليار دولار في نهاية ديسمبر V V. I ذللك وفقا والمركز المصرى للاراسات الأقتصادية، وهذه النتائج

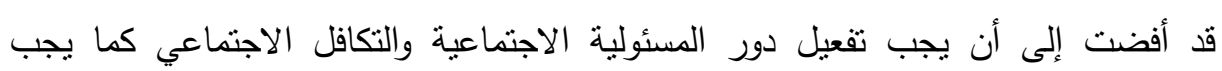
الاهتمام بسياسة التعليم وجودنه ونوعيته وأهميته بالنسبة لسوق العمل.

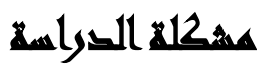

لقد تتاولت بعض الدراسات السابقة موضوع سياسات سعر الصرف وآثاره المختلفة على

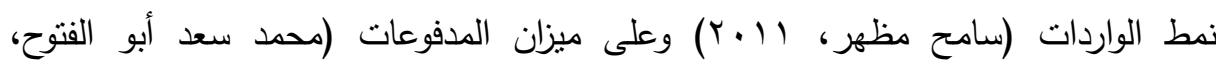

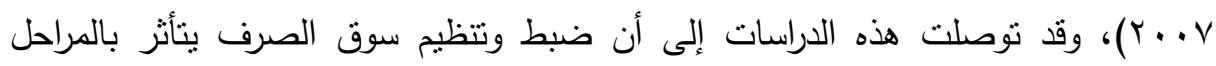

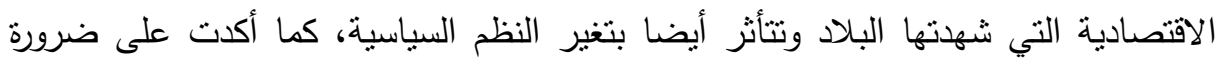

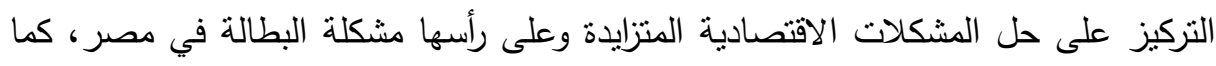
شهدت الفترة الأخيرة تقلبات كثيرة لسعر الصرف صاحبها ارتفاع ملحوظ في معدلات التضخم وذللك متمثلًا في حدوث ارتفاع متواصل ومستمر في المستوى العام للأسعار كما تعرضت كثثر من الثركات إلى الإفلاس وتسريح العمالة مما أدى إلى ارتفاع نسبة البطالة وبالتالي أثن ذلك على التتمية الاقتصادية وعلى تحقيق التتمية المستدامة.

\begin{tabular}{|c|c|c|c|c|c|}
\hline & & & \multicolumn{3}{|c|}{ يدول رقم(1): حجم البطالة وسعر الصرف في مصر } \\
\hline $\begin{array}{l}/ Y .17 \\
r .1 V\end{array}$ & $\begin{array}{l}/ r .10 \\
r .19\end{array}$ & $\begin{array}{l}\mid r .1 \varepsilon \\
r .10\end{array}$ & $\begin{array}{l}/ r+1 r \\
r+1 \leqslant\end{array}$ & $r+11 / r+1 \cdot$ & العام \\
\hline 11,9 & $1 Y, 0$ & $I Y, V$ & $1 \mu, r$ & $11, \Lambda$ & حجم البطالة \\
\hline $1 \wedge, Y^{\prime}$ & $\Lambda, \wedge \wedge$ & $V, 71$ & $V, 1 \varepsilon$ & $0,9 \xi$ & سعر الصرف \\
\hline
\end{tabular}

حيث يوضح الجدول رقم (1) حجم البطالة المقدرة في مصر وذللك عن الفترة من

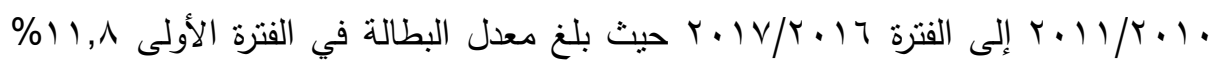

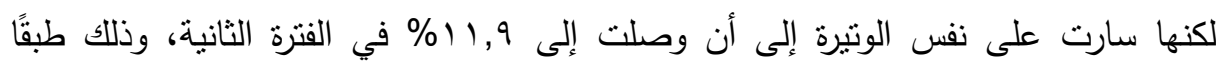

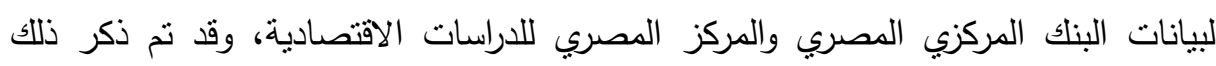

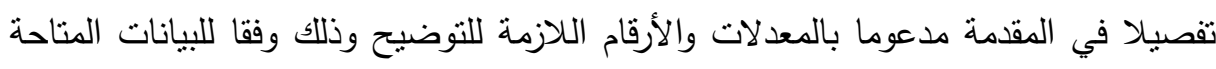
من التقارير السنوية والنشرات الثهرية والمجلات الاقتصادية الصادرة عن البنك المركزي 
ومن هنا تتلخص إثكالية البحث في محاولة التعرف على الآثار المترتبة على التغيرات

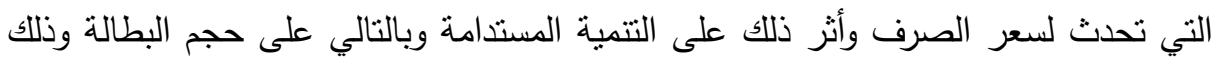
للحفاظ على العنصر البشرى كأحد أهم أبعاد التتمية المستدامة.

\section{أسئل التورامد}

ما علاقة التغيرات التي تحدث في أسعار الصرف على التتمية المستدامة وانعكاس ذلك على حجم البطالة في مصر؟ مأغيرآ ويندرج تحت هذا التساؤل الرئيسى أسئلة فرعية يمكن صياغتها كالتالى:

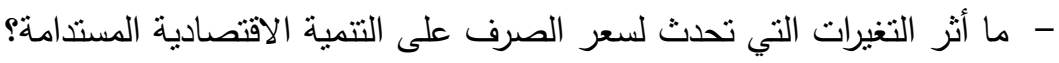

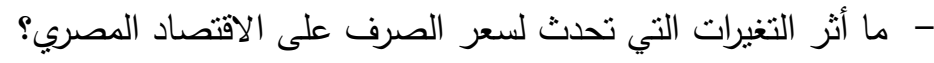

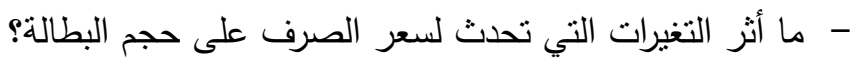

\section{أهساهيم الترواسما}

إن هدف الدراسة هي محاولة وضع لبنة بسيطة في هذا الموضوع الحيوي والمحوري، وذلك لمحاولة الوصول إلى التتمية الاقتصادية المستدامة ولعرض الموضوع بصورة واضحة

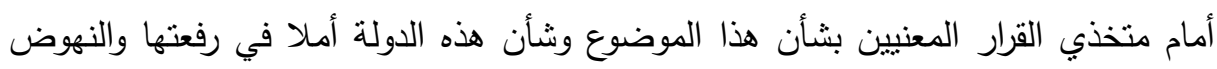
بها والعلو من شأنها، ولمحاولة مواكبة التغيرات العالمية التي تحدث على الساحة الآن وذلك من خلال تحقيق الأهداف الفرعية التالية: - تحليل الآثار الإيجابية والسلبية الناتجة عن التغيرات التي تحدث لسعر الصرف وأثر ذلك على التنمية المستدامة. - محاولة الوصول إلى الأسباب التي تنؤدي إلى التغيرات في سعر الصرف للمساهمة في عملية التتمية الاقتصادية وتحقيق التتمية المستدامة. - استعراض سياسات سعر الصرف وأهميتها في النشاط الاقتصادي، من خلال تتاول الإطار النظري طبيعة ومفهوم سياسات سعر الصرف، مع التعرض لسعر الصرف في

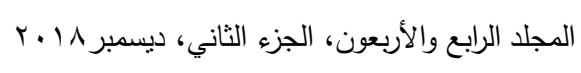


أدبيات الفكر الاقتصادي ونظرياته، والعوامل المؤثرة في سعر الصرف وكيفية تحديد هذه

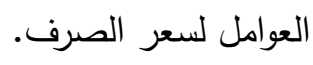

- أسواق الصرف وأغراضه والمتعاملون وأخيرا نعرض سعر الصرف كمتغير اقتصادي

$$
\text { محوري في النشاط الاقتصادي المصري. }
$$

\section{هزوضر التواسما}

إنساقًا مع الفرضيات السابقة فإن الباحثة تعرض عدة فروض تحاول من خلالها الأجابة

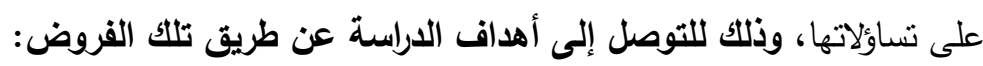
- توجد علاقة سلبية تؤثز على حجم البطالة وبالنالى على تحقيق التتمبة المستدامة وذللك

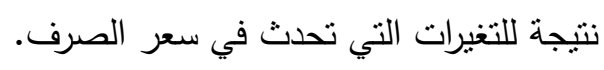

- توجد علاقة سلبية تؤثر على معدلات الاستثمار نتيجة لحدوث تغيرات في سعر الصرف.

\section{حبوض الصواسما}

أ- الحدود الزمنية: دراسة أثز التغيرات التي تحدث لسعر الصرف على التتمية المستدامة

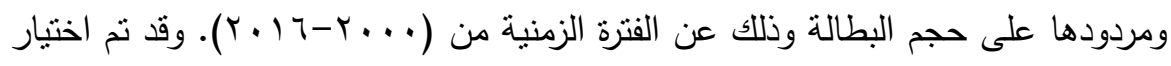
هذه الفترة الزمنية لأنها ضمت قرارات من أهم القرارات التي لها أنز على الإنى الاقتصاد

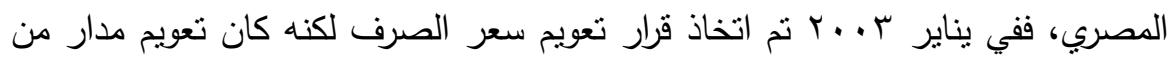

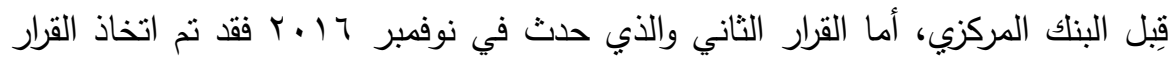
الثاني وهو تحرير سعر الصرف بشكل كامل وتركه لميكانيزم السوق، وبناء على ذللك نم تحديد هذه الفترة الزمنية نظرا لأهميتها. ب- الحدود المكانية: تتتاول الدراسة الوضع الاقتصادي داخل جمهورية مصر العربية من خلال ما تم الرجوع إليه في الدراسة التحليلية لمعرفة أثر تغيرات سعر الصرف على التتمية

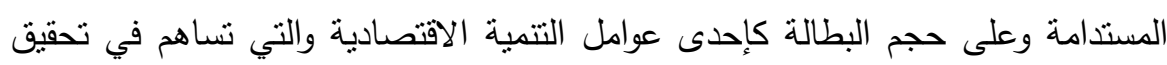




\section{منهمج الدراهم}

إن دراسة موضوع "أنز تغيرات سعر الصرف على التتمبة المستدامة وانعكاسه على حجم البطالة" بمختلف جوانبه ومتغيراته ومحاولة الربط بين هذه المتغيرات يجعلنا نستخدم المنهج

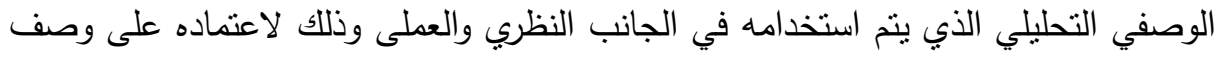

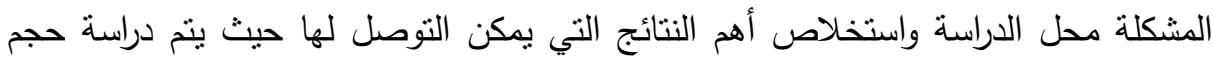
البطالة ومدى نأثرها بتغيرات سعر الصرف وأثر ذلك على التتمية المستدامة.

\section{أهمية الصراسمة}

تتمثل أهمية الدراسة الحالية في سعيها للتعرف على : أثر تغيرات سعر الصرف على التتمية المستدامة وإنعكاس هذا الأثر على حجم البطالة في مصر ، من خلال الأهداف التالية:

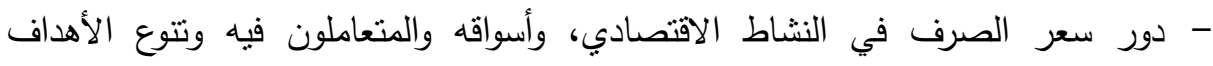
والأغراض في تلك الأسواق. - سياسات سعر الصرف وأهمتها في تحديد سعر الصرف. - العوامل المؤثرة في سعر الصرف وانعكاسه على النشاط الاقتصادي. - سعر الصرف كمتغير اقتصادي محوري في النشاط الاقتصادي المصري.

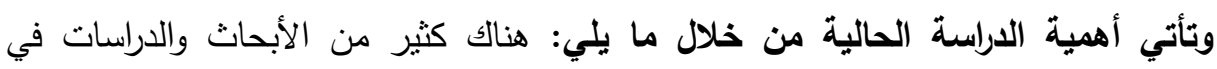

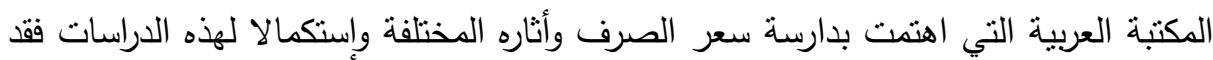
أثثر القيام بعمل دراسة عن أثز تغيرات سعر الصرف على حجم البطالة وإنعكاس ذلك ألاثر على التتمية المستدامة وذللك بعد القرار ألأخير لتحرير سعر الصرف بشت بشكل كامل حيث بيتقيد

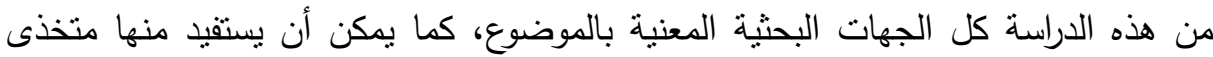
القرار في مصر المعنيين بالتتمية المستدامة وذللك في محاولة من الباحثة في المساهمة ولو بها

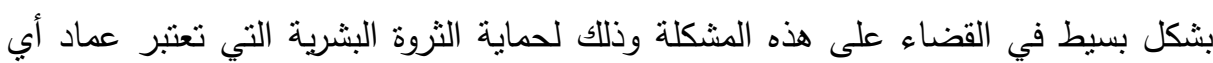




\section{همسلحائ التوراسما}

- سعر الصرف: عبارة عن عملة مقومة بعملة أخرى أى قيمة الوحده من هذه العملة مقومة

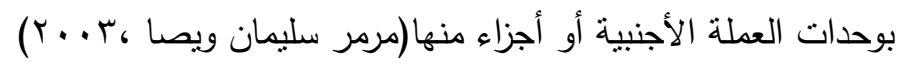

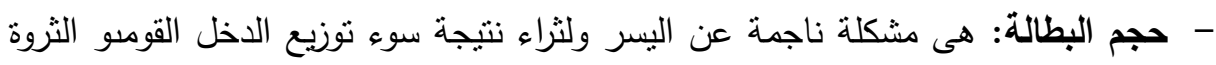

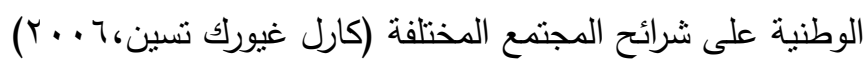

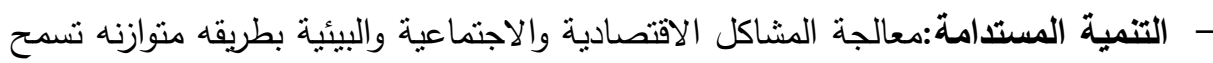
بتلبية حاجات أجيال الحاضر من دون المساس بقدرة أجيال المستقبل على تلبية حاجاتها"

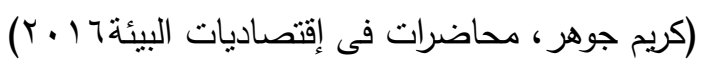

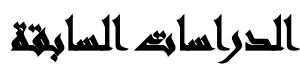

تهذف الباحثة من خلال هذه الدراسات إلى عرض الأفكار والمفاهيم الأساسية التي تتاولتها هذه الدراسات، ثم استخلاص الملاحظات من خلال مراجعة الدراسات.

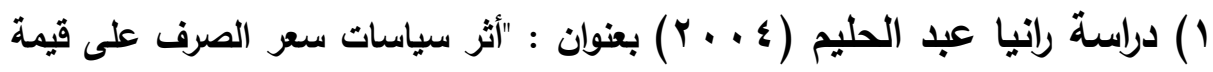
الجنية"، رسالة ماجستير، كلية التجارة جامعة عين شمس.

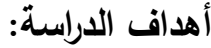

$$
\text { - - دراسة دور سياسة الرقابة على سعر الصرف. }
$$

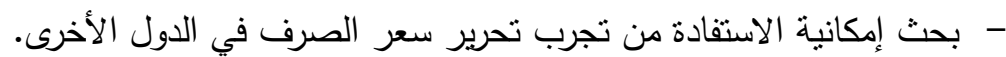
- اقتراح استراتيجية متكاملة لمساندة قرار تحرير سعر الصرف.

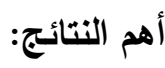
- يعتبر تحول مصر من نظام سعر الصرف الثابت إلى نظام سعر الصرف المرن ملائمًا

$$
\text { لظروف الاقتصاد المصري. }
$$
- ضرورة اتخاذ حزمة من الإجراءات لإصلاح الأوضاع الاقتصادية السائدة حتى يحقق تحرير الجنية المصري هدفة من الاستقرار . 


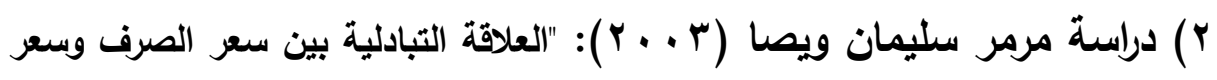
الفائدة في ظل المتغيرات الاقتصادية"، رسالة ماجستير ، كلية التجارة جامعة عين شمس.

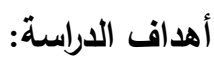

- التعرف على سياسات سعر الصرف والتعرض إلى العوامل التي تؤثر في تلك السياسات. - توضيح سياسات سعر الفائدة وتحليل العوامل المؤثرة فيها. - تفسير أثر التغيرات المنبادلة بين سعري الصرف والفائدة. أهم النتائج:

- عمل إصلاحات شاملة في الاقتصاد المصري ككل وتهيئة المناخ الاقتصادي الملائم للتنمية.

- - إعادة النظر في سياسات التجارة الخارجية.

- العمل على رفع مستوى جودة الصادرات المصرية لزيادة قدرتها التنافسية.

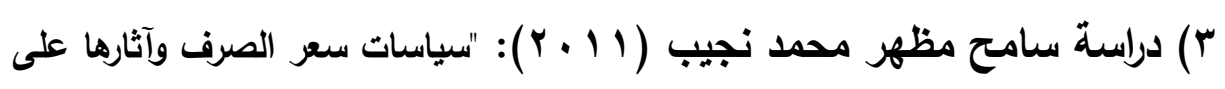
نمط الواردات"، رسالة ماجستير، كلية التجارة جامعة عين شمس.

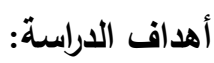
- دراسة أثز سياسات سعر الصرف على العجز في الميزان التجاري.

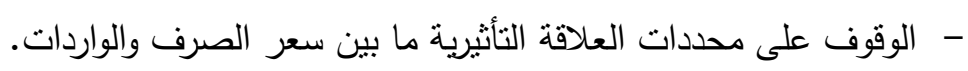
- تحديد أفضل سياسة من سياسات سعر الصرف التي نم تطبيقها في مصر للإبقاء عليها.

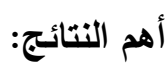
- - يوجد تضارب في القوانين والقرارات المتلاحقة بشأن تتظيم سوق الصرف. - توصلت الدراسة إلى عدم كفاءة سوف الصرف الأجنبي في مصر . - ارتبط ضبط وتتظيم سوق الصرف بالمراحل الاقتصادية التي شهدتها مصر وتأثز أيضًا بتغيير النظم السياسية للاولة. 


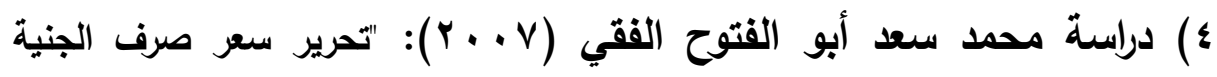

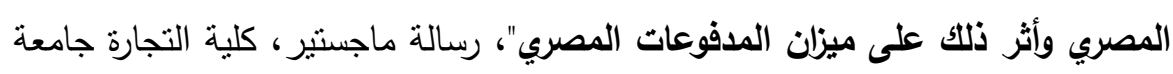

$$
\text { أهداف الدراسة: شمس. }
$$

- معرفة أهمية سياسات سعر الصرف وأثنارها على حالة ميزان المدفوعات.

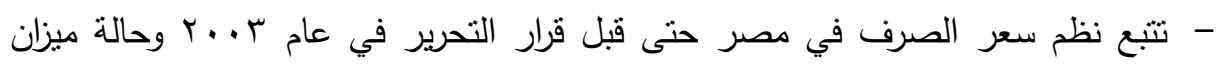
المدفوعات عن نفس الفترة.

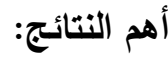

- التحسن الذي حدث في ميزان المدفوعات المصري في النصف الأول من التسعينات لم يكن من تأثير سياسة سعر الصرف فقط ولكن بسبب أدوات السياسة النقدية.

- مصادر الحصول على النقد الأجنبي ليست مصادر ثابتة لكنها شديدة الحساسية للصدمات لئل

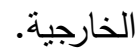

- ربط الجنية بالدولار كان من أكبر الأخطاء حيث أن التغيرات في الجنية مقابل العملات

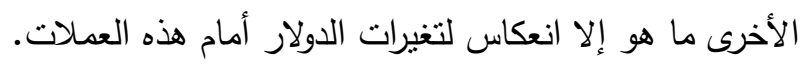

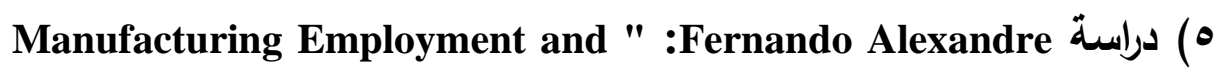
Exchange Rate in the Portuguese economy: The role of openness,

"Technology and labour market rigidity

أهداف الدراسة: دراسة أثز سعر الصرف على قطاعي التصنيع والعمالة وذلك في ظل الانفتاح التجاري والتكنولوجي.

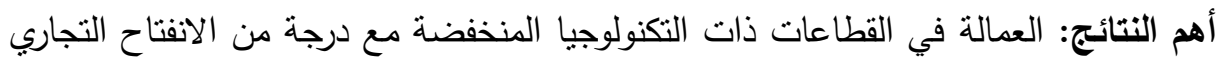
تكون أقل صلابة في سوق العمل ومعظمها يتأثز بتطور سعر الصرف منذ أواخر الثمانينات.

The Unemployment Effect of " :Dr. Horst Feldmann دراسة "Exchange Rate Volatility in Industrial Countries أهداف الدراسة: دراسة أثر تقلبات سعر الصرف على البطالة. 
أهم النتائج: أهمية السيطرة على جميع العوامل الرئيسية التي تؤثر على معدل البطالة مثل

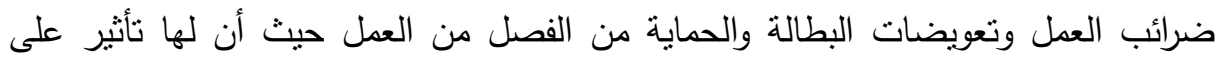

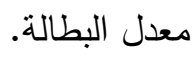

\section{إجراعايه الدراهم}

تم الحصول على البيانات التي تخص البحث من خلال وثائق مكتبات البنك المركزي

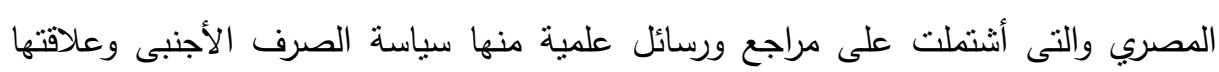
بالسياسة النقدية لعام • ( • ؟، والمركز المصري للاراسات الاقتصادية الذى أثنمل على سلسلة

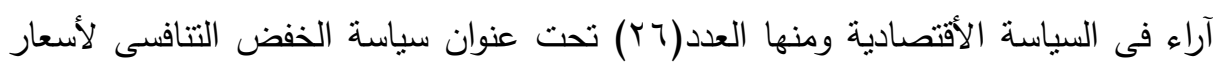
الصرف العالمية وآثارها على الصادرات المصرية، ومكتبة البنك الأهلي المصري والتى

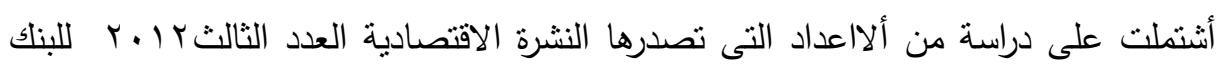

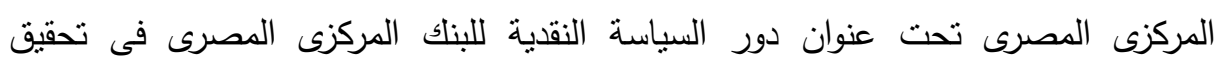

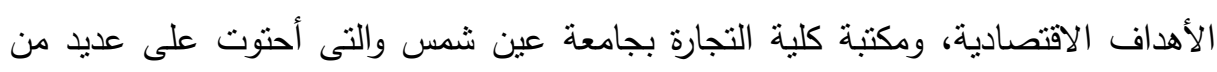

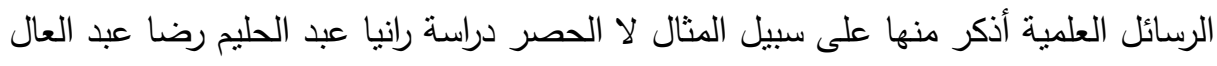

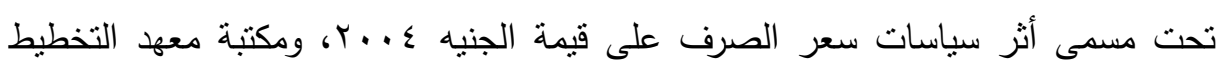

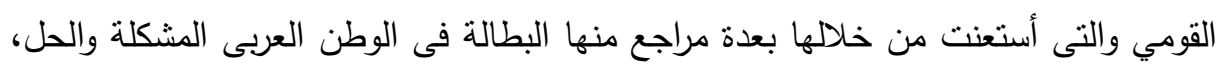

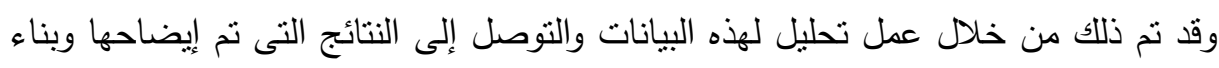
على ذللك تمت كتابة التوصيات اللازمة.

\section{الإطار اللنظيه}

المبحث الأول: سعر الصرف

أولا: سياسات سعر الصرف: يشهد العالم نطورات حديثة وسريعة ويلعب سعر الصرف دورا هاما في تحدياتها، حيث يعتبر عامل مؤثر في التقلبات الاقتصادية، فنحن هنا بصدد متغير

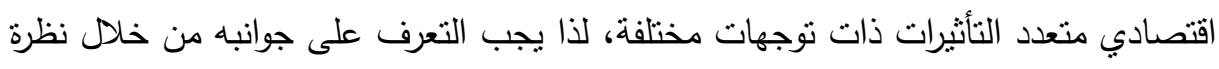

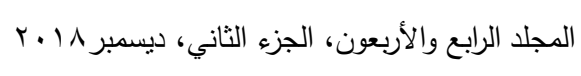


شاملة. فسعر صرف عملة دولة ما يرتبط باحتياطياتها من الذهب، وبأصولها الخارجية، وبقوة

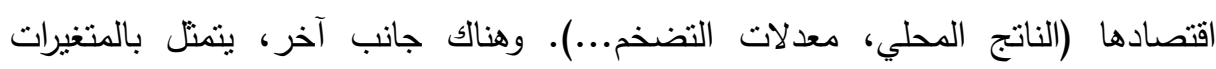
السياسية.

1 - تعريف سعر الصرف:يعرف سعر الصرف بأنه " عبارة عن عملة مقومة بعملة أخرى" أي

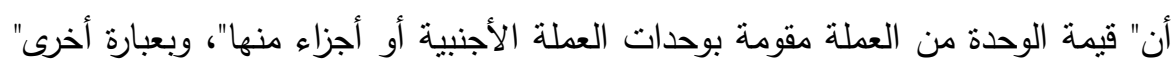

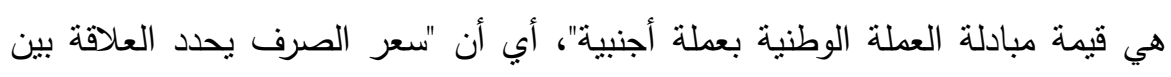

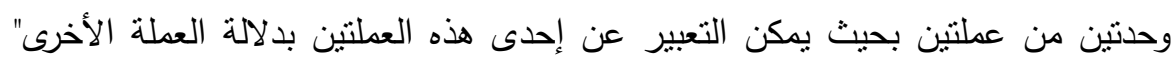

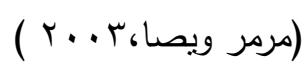

r - مفهوم سعر الصرف:تتوعت مسميات سعر الصرف تبعا للسياسة والأنظمة الاقتصادية

$$
\text { المطبقة وهي: المغون: }
$$

ا. سعر التعادل: سعر رسمي اتفاقي وضع أسسه في اتفاقية إنثاء صندوق النقد الدولي عام

r. سعر تجاري: سعر صرف محدد يستخدم في التبادل التجاري بين الدول لتسهيل وتتشيط

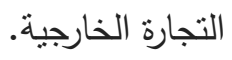

r. سعر مالي: بحدد من قبل الدولة لتحويلات رأس المال منها وإليها. صرف إداري.

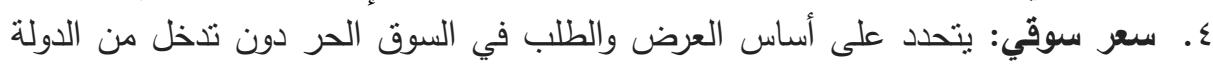
في تحديده أو التأثنر عليه.

ب- طرق إعلان سعر الصرف: يتم إعلان سعر صرف العملات الدولية بإحدى الطريقتين:

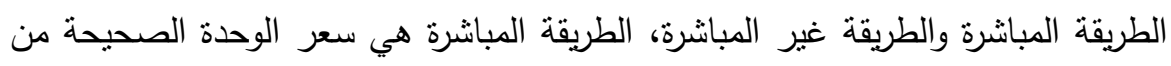

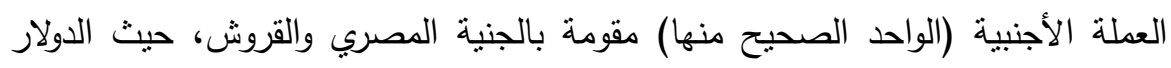
الأمريكي حوالي ·. †, جنيه مصري وأيضًا تسمي هذه الطريقة بنظام التسمية السعرية.

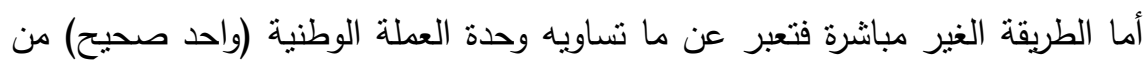

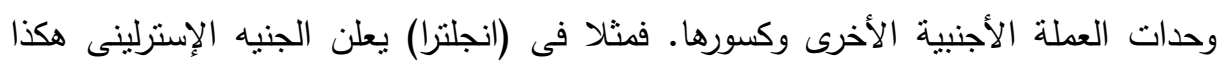

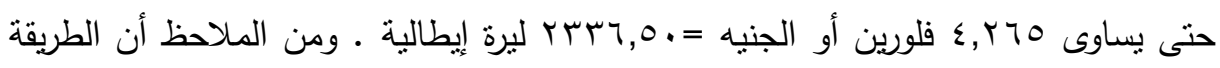
المباشرة هى الأكثر شيوعا وأستخداما فى الوسط الدولى وتسمى هذه الطريقة أيضا بالطريقة 
ثانيًا: أسواق سعر الصرف الحرة: ينقسم سوق الصرف تبعا لنوع العمليات التي تتم به، فهناك

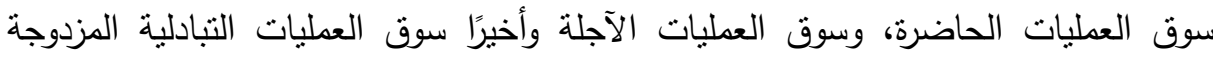
(المقايضة). 1- السوق الحاضرة (Spot Exchange Market): تعتبر من أهم أسواق الصرف، تتم

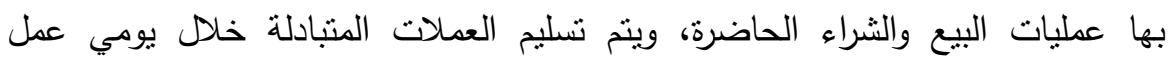
بالإضافة إلى يوم التعاقد، وأسعار العمليات الحاضره هى الأسعار الأساسية التى يتحدد لئمداه على أساسها أسعار السوقين الآخرين.

ب- السوق الآحلة (Forward Exchange market): يتم الاتفاق على البيع والثراء

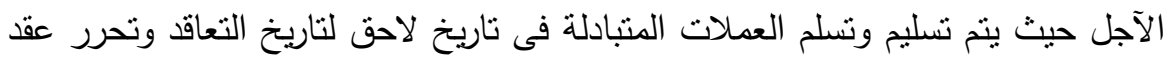

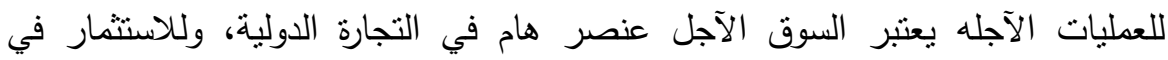
الأصول المالية المقومة بالعملات الأجنبية، حيث يتم بواسطة العمليات الآجلة التغطية والتأمين ضد مخاطر تقلبات أسعار الصرف. بأ. ب- سوق المقايضة (Swap Market): تختص هذه السوق بعمليات المبادلة ولكن مع اختلاف زمن البيع عن الثراء، أو العكس فيتم شراء أو بيع عملة مقابل عملة أخرى في

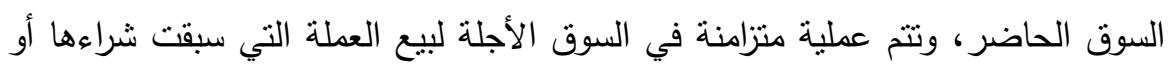
شراء العملة التي سبق بيعها في السوق الحاضرة.

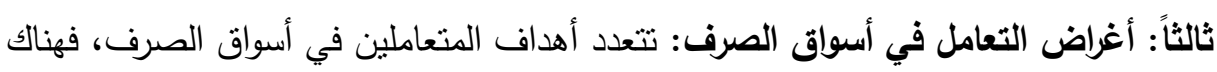

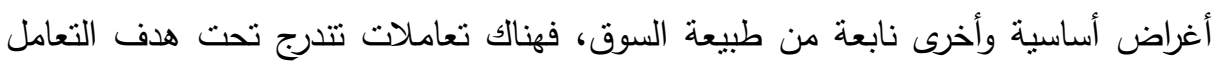

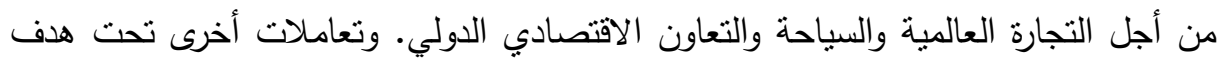

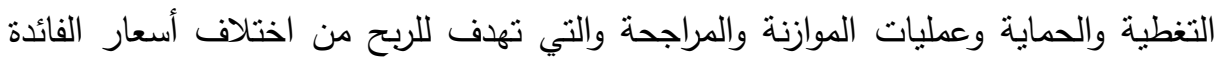

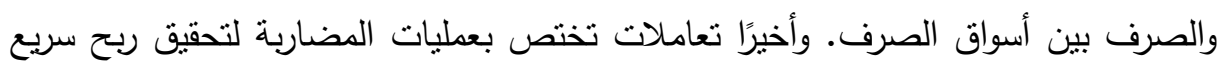
ولكنها تضر أسواق الصرف ونظام النقد الدولي. 
1- عمليات التغطية Coverage Processing: تهدف تغطية العمليات الخاصة بنبادل عملات مختلفة أو تبادل أصول مقومة بعملات متتوعة، وذللك بتحويل مقابل أصول تفولة

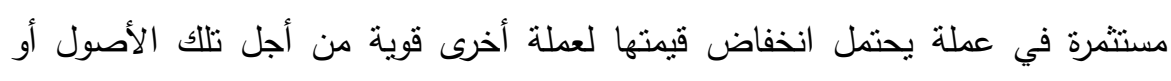
الحقوق وبنفس الكيفية، وبنفس الكيفية تغطي الالتزامات المقومة بعملات يتوقع (يخشي)

$$
\text { ارتفاع أسعار صرفها. }
$$

ب - عمليات الموازنة Arbitrage Processing: يقصد بها العمليات التى تهدف إلى إلى تحقيق ربح من الفارق السعرى بالنسبة لسعر صف علة معينة بين سوقين صرف أو اكثر

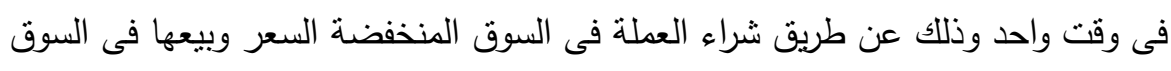

$$
\text { مرتفعة السعر }
$$

فإذا كان سعر صرف الدولار في سوق الصرف بالقاهرة (عام ra19 العلى سبيل المثال)

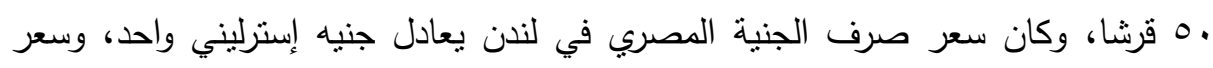

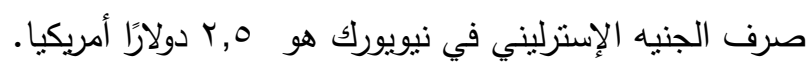

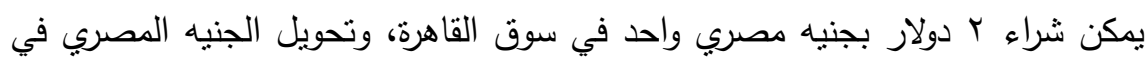

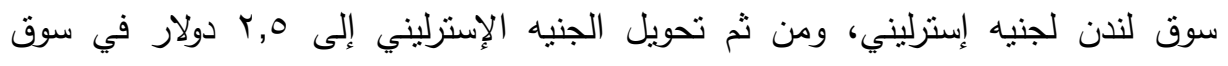

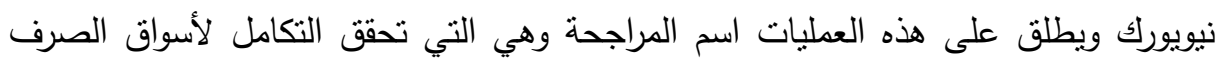

$$
\text { المختلفة، حيث يسودها سعر واحد للصرف مهما كان بعدها الجغرافي. }
$$

r- عمليات المضارية Processing Speculation: المضارب هو الذي يخاطر بمركزه المالي لتحقيق أقصى ربح وذللك بشراء وبيع عملة ما في سوق الحاضر والآجل تبعًا

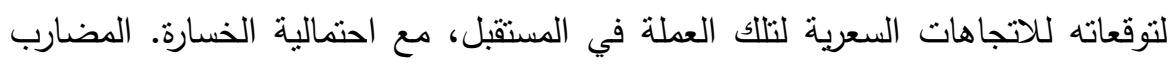

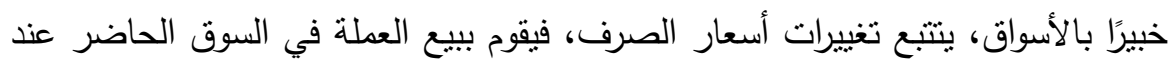
احتمال انخفاض سعرها في السوق الآجل، مقابل إحدى العملات القوية وشرائها فيما بعد.

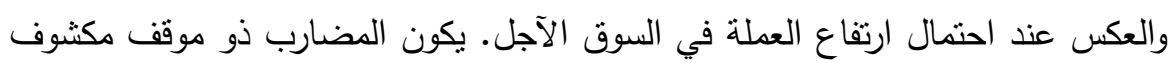

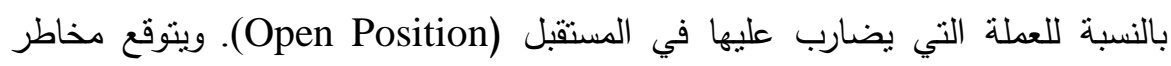
تقلب أسعار صرف العملات في المستقبل بالنسبة لأسعارها الحالية. ويتوقف مقدار ربح

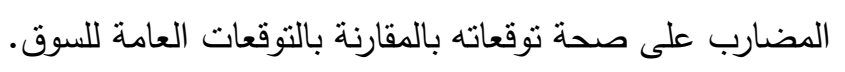


رابعًا: العوامل المؤثرة في سعر الصرف: يتأثر سعر الصرف بالعديد من المتغيرات الدولية،

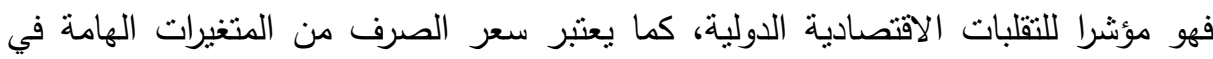
العالم الاقتصادي ذو التأثير المتبادل، فهو يتأثز ويؤثر في العوامل المحددة له وفي مكوناته. وفيما يلي أهم العوامل التي تؤثر في سعر الصرف: تتعدد العوامل التي تؤثر في سعر الصرف، تختلف تأثنيرها من عامل لآخر .

1- ميزلن المدفوعات: يعتبر ميزان المدفوعات من العوامل المؤثرة في سعر الصرف، حيث

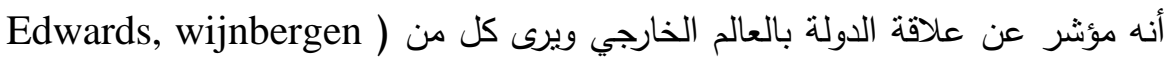
1998) أن تأثثر ميزان المدفوعات على سياسات سعر الصرف بالتخفيض نتيجة العجز

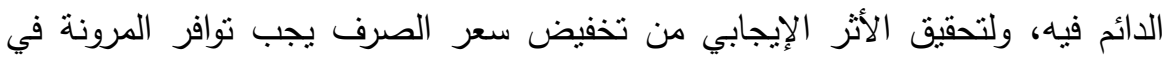
الصادرات والواردات، وتؤيده أيضا دراسات أخرى لبعض الإبه من الاقتصاديين مثل جولدستين، لكن

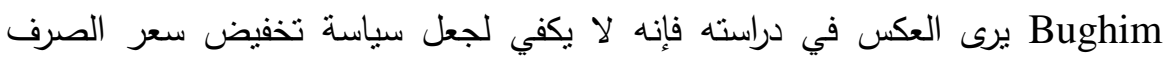

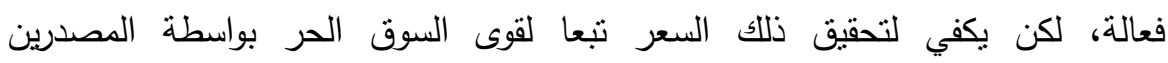
والمستوردين (المحليين والأجانب).

في الأسواق الدحلية والأجنبية، وهناك بعض الاجناته الدراسات التي تفسر الطفرات الحادثة في بعض موازيين مدفوعات من الدول النامية، ليس على أساس توافر شرط المرونة فقط، بل أيضا على أساس هيكل أسواق التجارة الخارجية وتسعير سلع التبادل التجاري. كما تؤثر

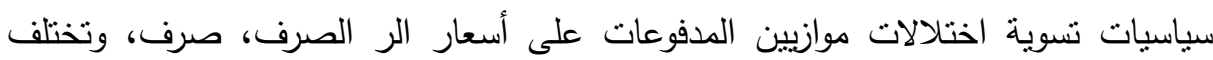

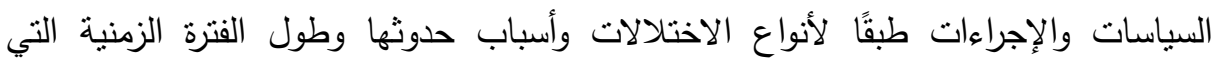
تأخذها، ومن الاختلالات التي تصيب موازين المدفوعات هي: الاختلال العارض - الاختلال الموسمي - الاختلال الدوري - الاختلال الهيكلي

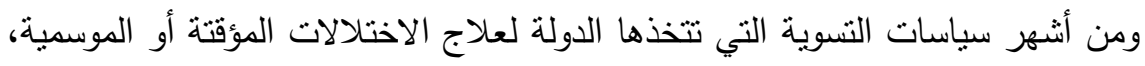
السحب من الاحتياطيات الذهب أو الصرف الأجنبي، ولكن هذه الطريقة محدودة الفاعلية نظرًا

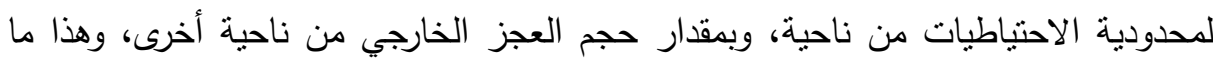
يؤثز سلبيا على احتياطيات الدولة من العملة الأجنبية، وعلى قيمة سعر صرفيه وبهن عملتها.

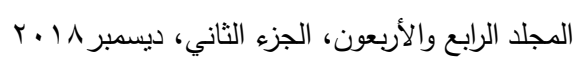


يعتبر الاختلال الهيكلي من أخطر وأقوي الاختلالات التي تصيب موازين المدفوعات، وتؤثر تأثيرًا قوبي على سعر الصرف، وهناك عدد من السياسات التصحيحية لعلاج الاختلال

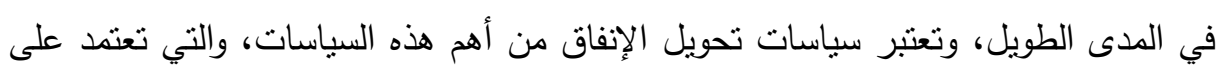

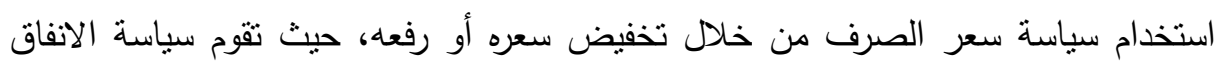
علي تخفيض الواردات وزيادة الصادرات، وذلك بتخفيض سعر الصرف لتحويل طلب المقيمين

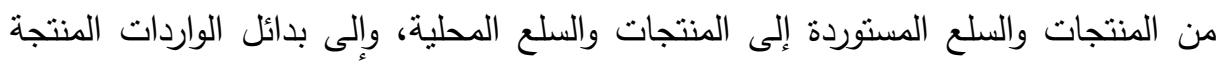
محليا، وأيضًا زيادة الصادرات بتحويل الطلب الخارجي إلى صادرات هذه الدولة.

r- الطلب على السلع والخدمات: تكون رغبة الأفراد فى شراء السلع والخدمات الأجنبية أساس الطلب على العملات الأجنبية وكلما زاد الطلب على شراء السلع والخدمات الأجنبية

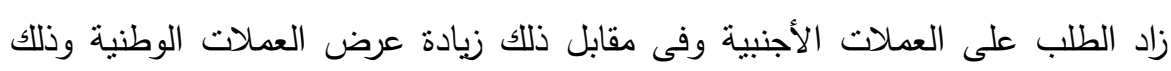
يؤثر فى سعر العملات الوطنية كما تمتل الواردات طلبا على السلع والخدمات الأجنبية

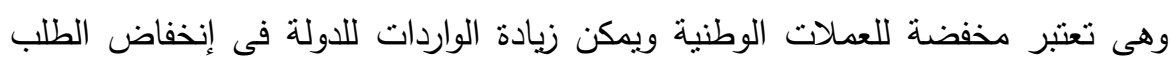
على السلع والخدمات المحلية أى انخفاض الطلب على العملات المحلية وهذا يعكس الطبل الحالة الأقتصادية للدولة .

ب-السباسات المالية والنقبية Fiscal and Monetary Policies: من العوامل المؤثره فعى سعر الصرف السياسات المالية والنقدية ( Fiscal and Monetary policies ) تعتبر الضرائب من السياسات المالية فالضرائب التى تفرض لمحاصرة التضخم تساعد على تحسين أسعار الصرف فهى تمنل إيرادات الحكومة حيث تعمل على تخفيض العجز

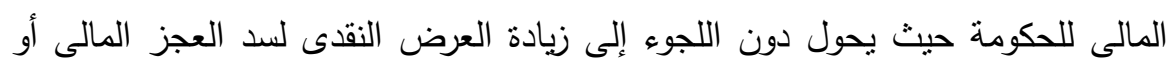

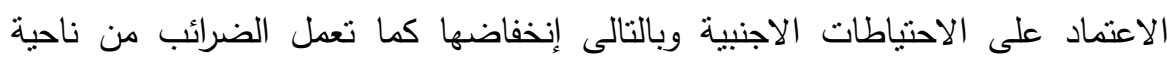

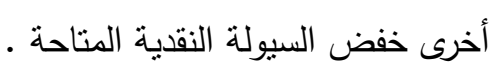
ع -التضخم inflation: بعتبر التضخم من اخطر الاختلالات التى تصيب اقتصاديات الدول

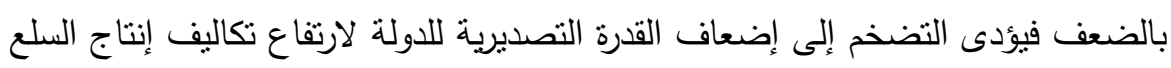

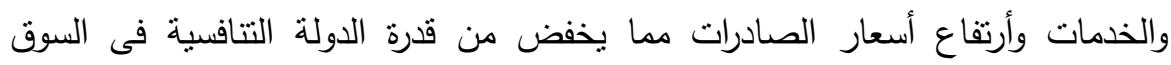


الخارجية وهو ما يؤدى إلى ضعف قدرة الدولة على تدبير التمويل اللازم للتتمية من

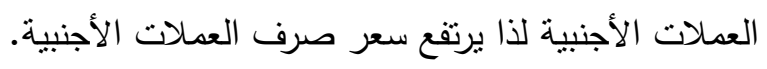

المبحث الثاني: البطالة في مصر

المقدمة: البطالة هي واحدة من المشاكل التي تواجه الاقتصاد العالمي بشكل عام واقتصاد

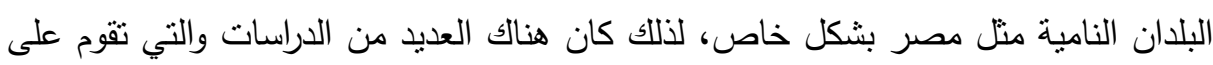
التحقق في المتغيرات التي تؤثر على البطالة في الاقتصاد الكلي، وبالنظر إلى تقلبات أسعار

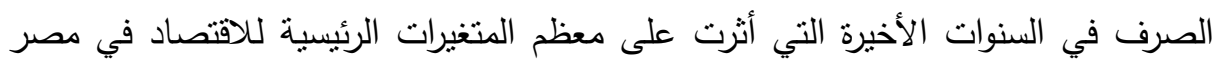
فقد حاولت هذه الدراسسة معرفة العلاقة بين سعر الصرف والبطالة في مصر وذللك عن طريق التئي

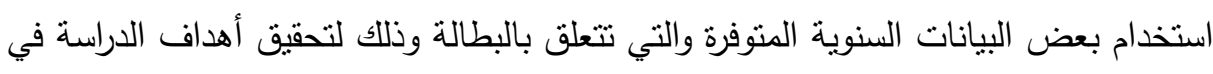

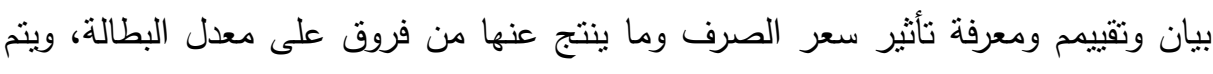

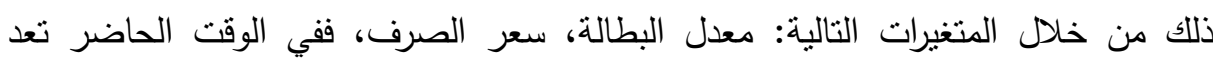

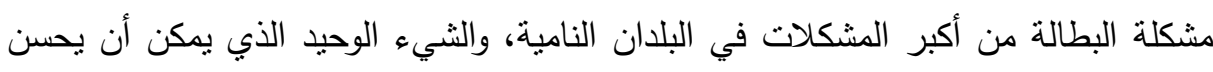
الظروف الاقتصادية السيئة في هذه المجتمعات هو الاقتصاد النشط والذي يمكن أن يؤثر البز

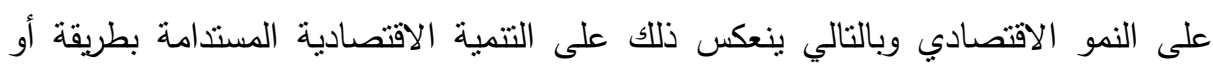
بأخرى.

فالمشكلة الناجمة عن البطالة أكثر وضوحا في البلدان النامية لاسيما اللدان التي لم تنتبأ

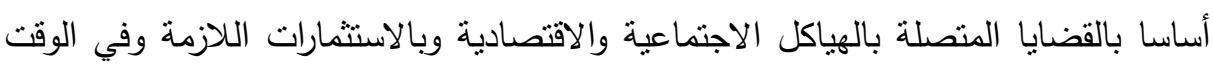
المناسب.

حيث يشكل استخدام القوى العالمية البشرية مسألة هامة تتصل بعدة عوامل، فمن ناحية

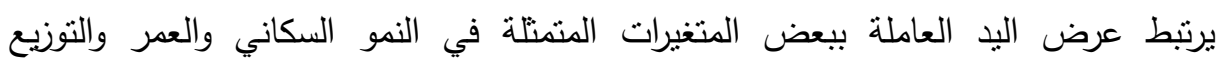
الجغرافي للسكان والهجرة ومعدل مشاركة المرأة، ومن ناحية أخرى يرتبط الطلب على لئى اليد اليد

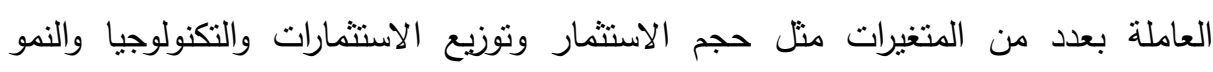
الاقتصادي وكل هذه المتغيرات ترتبط بثكل وثيق بالتتمية المستدامة لذلك فقد ارتأيت أن الن

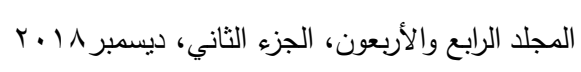




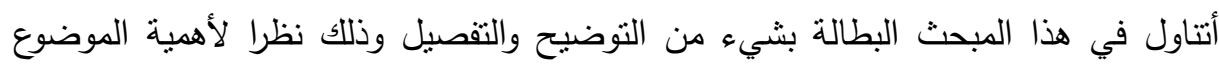

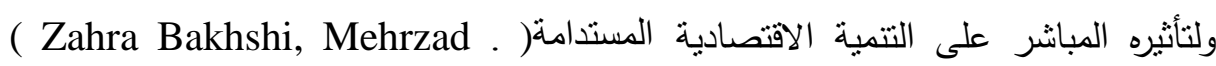

Ebrahimi

أولا: تعريف البطالة: هي كل شخص قادر على العمل وراغب فيه ويبحث عنه ولكن دون جوى.

كما عرف Fried Laender Pachtl البطالة بأنها: رأس مال خامد.

كما تم تعريف البطالة على أنها: النوقف الإجباري لجزء من القوى العاملة برغم قدرة ورغبة

هذه القوى على العمل والإنتاج.

وهناك من رأى أن البطالة ليست مشكلة ناجمة عن العوز والفاقة بل هي مشكلة ناجمة

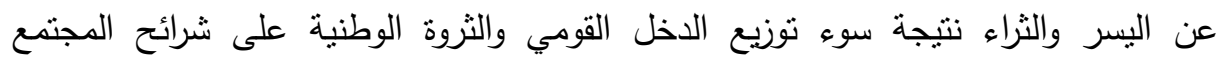

المختلفة.

فمن خلال التعريفات السابقة ترى الباحثة أن البطالة هي: الطاقة البشرية المتعطلة عن

العمل لأسباب شخصية أو سياسية أو اجتماعية أو تنظيمية أو فكرية أو اقتصادية.

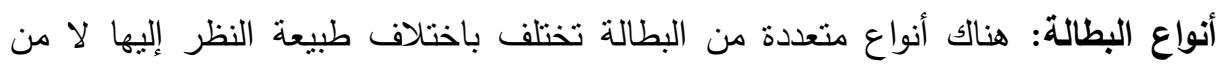

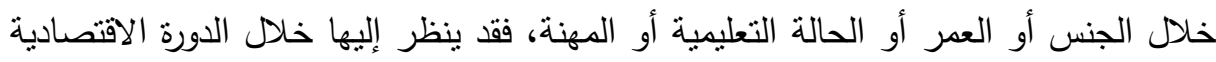

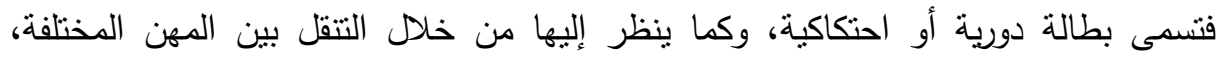

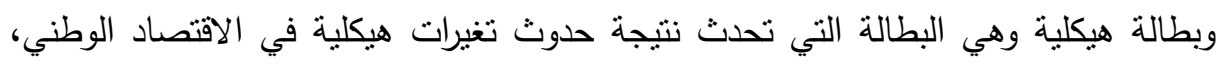

$$
\text { وكذلك هناك البطالة الموسمية أو العرضية. }
$$

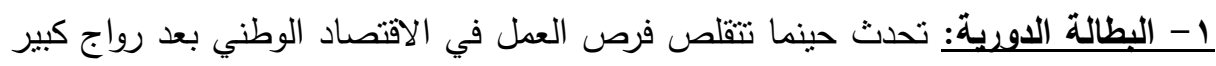

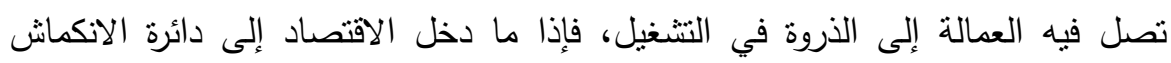

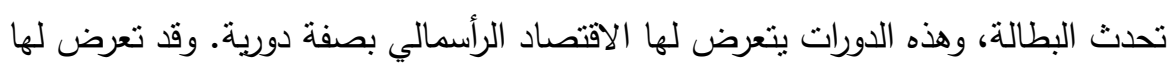

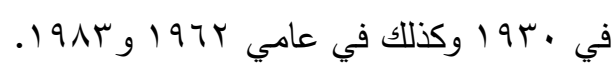

والبطالة الدورية في تعريف الأمم المتحدة هي نتيجة من نتائج فثل الطلب الاقتصادي

بسبب تغبرات في مستويات النشاط خلال فتزة معينة. 


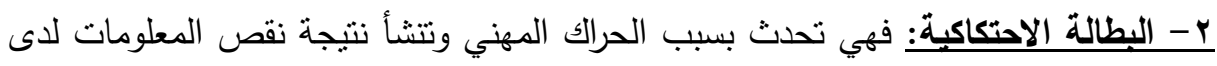

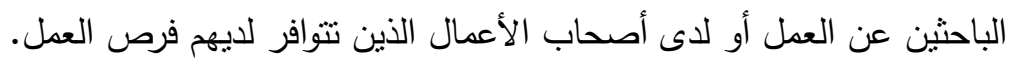

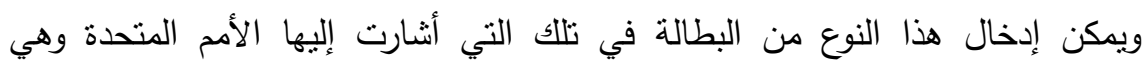

$$
\text { الخاصة بعجز الطلب الكلي للعمل على الاستفادة من العرض المتاح. }
$$

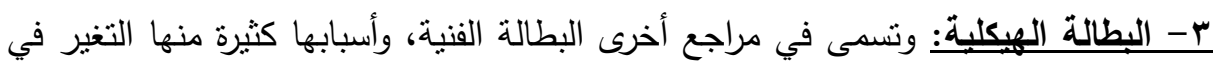
هيكل الطلب على المنتجات، فيترتب عليه تغير في هيكل العمالة المستخدمة أو إدخال تطور تقني معين في إعداد المكلفين بأداء العمل أو بسبب انتقال الصناعة من مكان إلى هيلى

ع- البطالة الموسمية أو العرضية: وهي بطالة تحدث خلال موسم معين أو بعد انتهاء عمل

$$
\text { عرضي معين متلما يحدث في محالج القطن أو في أعمال الثحن والتفريخ في الموانئ. }
$$

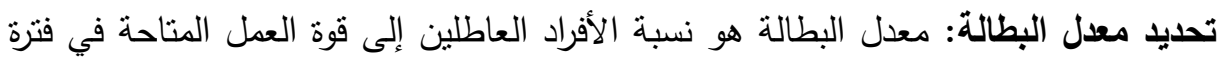
زمنية معينة، والكشف عن ذلكك المعدل ليس أمر سهل، حيث يمكن الكثف عن ذلك المعدل من خلال تعداد السكان في البلد الواحد، لكن ذللك يحدث على عشر سنوات في معظم البلاد

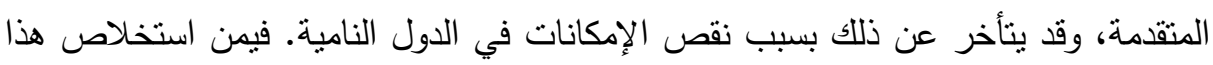

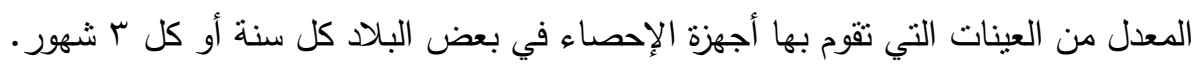
ففي مصر ينم احتساب معدل البطالة كالتالي:

$$
\text { عدد القاطلين العاملة }
$$$$
\text { معدل البطالة = }
$$

أي هو نسبة عدد الأفراد العاطلين إلى القوى العاملة الكلية وهو معدل بصعب حسابه بدقة حيث أن نسبة المتعطلين تختلف حسب الوسط (حضري - قروي) وحسب الجنس والسن

$$
\text { ونوع التعليم والمستوى الدراسي( ويكيبديا ، الموسوعة الحره ) }
$$

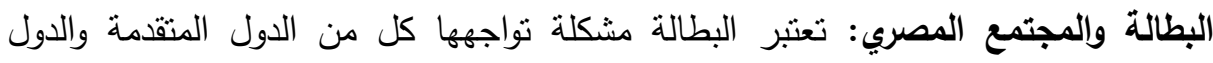
النامية على حد سواء، فقد ظهرت البطالة في معظم الدول ومنها على سبيل المثال الولايات

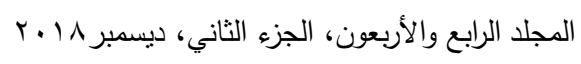


المتحدة الأمريكية، ظهرت نسبة البطالة بها بنسبة ,0,\%، كما ظهرت في المملكة المتحدة

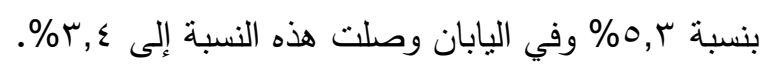

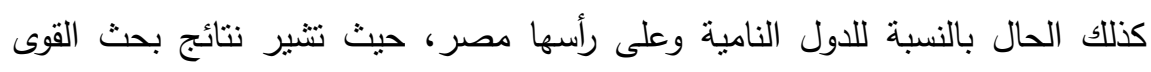

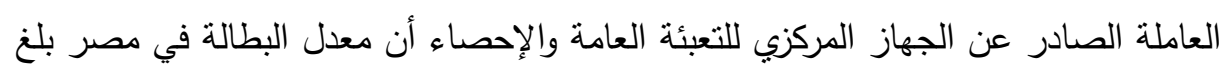
\%) r,o

ومع الاختلاف في طريقة التعامل مع هذه المشكلة في كلتا الحالتين حيث البنية

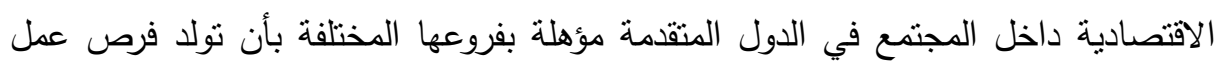

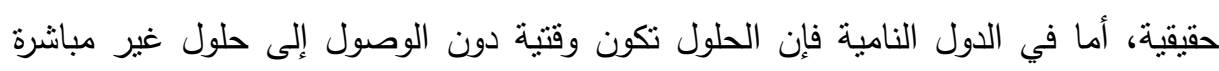

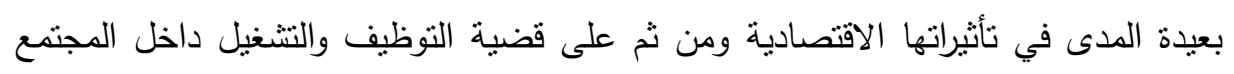
ومن ثم التأثثر بشكل مباشر على التئمية الاقتصادية المستدامة. 


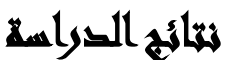

من خلال ما تم عرضه سابقًا استخلصت الباحثة النتائج التالية فيما يلي:

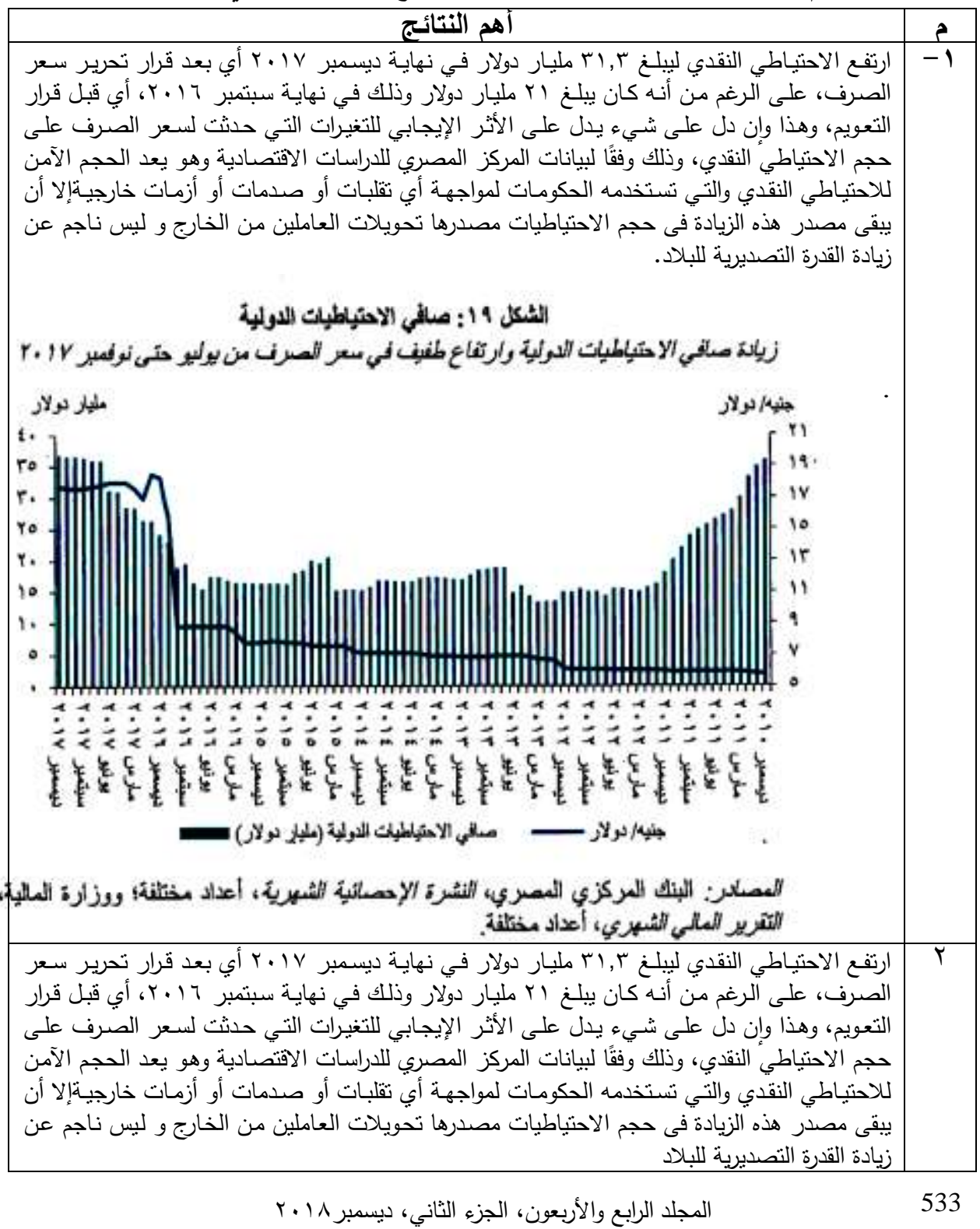




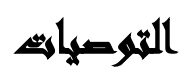 \\ وفي ضوء النتائج السابقة تقترح الباحثة بعض التوصيات كالآتي:}

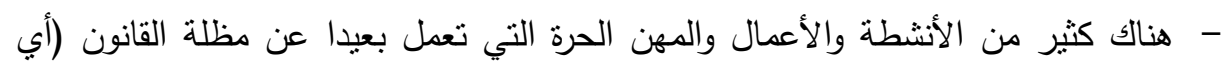

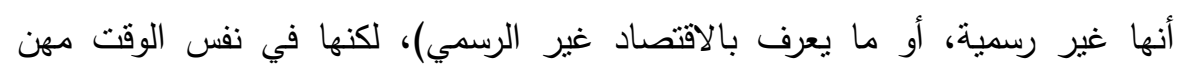

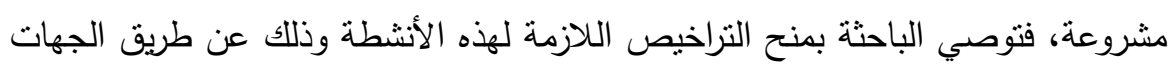

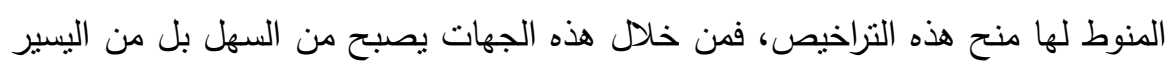

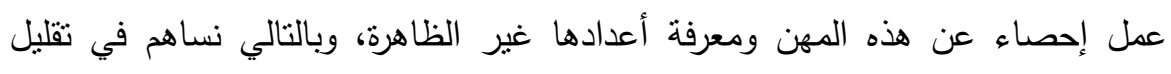

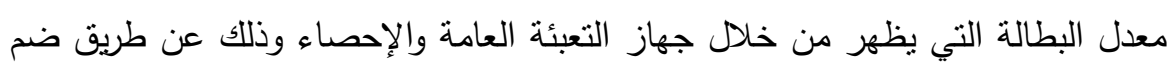
نسبة غير قليلة من العمالة والمهن الحرة غير المسجلة ويصعب حصرها، وبذللك يصبح الاقتصاد غير الرسمي اقتصادا رسمبا معلنا وواضحا سهل حصره وضمه الحير إلى الأثشة الرسمية، فيظهر معدل البطالة بشكل أقل نسبيا.

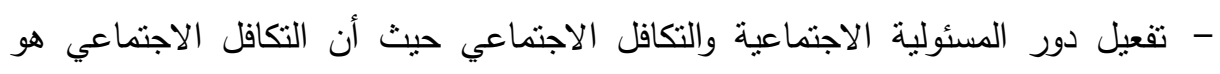

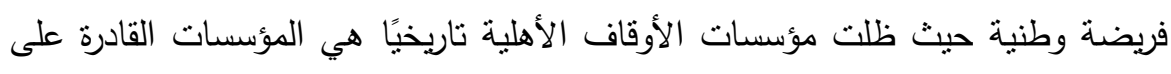
تمويل الأنشطة الاجتماعية من خلال تطبيق دور المسئولية الاجتماعية وتذليل أي عقبات

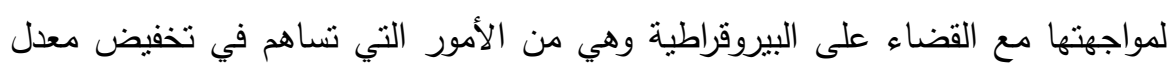
البطالة والمساعدة على زيادة التتمية الاقتصادية المستخامة. - الاهتمام بسياسة التعليم وجودته ونوعيته وأهميته بالنسبة لسوق العمل.

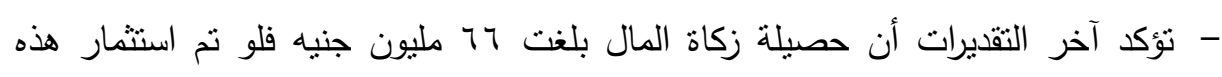

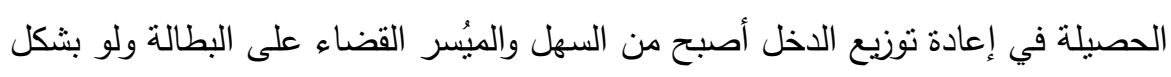

$$
\text { نسبي. }
$$
- الصناعة والإنتاج هي عماد أي دولة لحل مشكلة البطالة والقضاء عليها ولضمان تحقيق

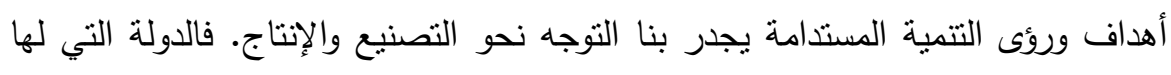
القدرة على التصنيع هي الدولة التي تملك مقدراتها. 


\section{هائمة المرالجية}

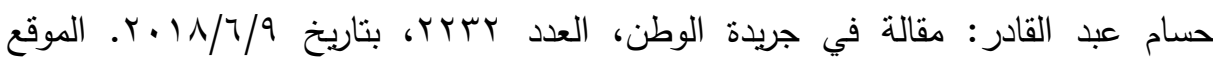
الإكتروني: www.alwatannews.com.

خالد محمد الزواوي: البطالة في الوطن العربي، المشكلة والحل، معهد التخطيط القومي، مركز التوثيق والنشر النش

كارل غيورك تسين(T + . ץ): الرخاء المفقركتبة كلية تجارة عين شمس. كريم جوهر (7 ( • Y): محاضرات فى إقتصاديات البيئة.

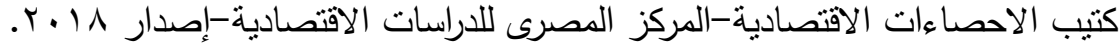

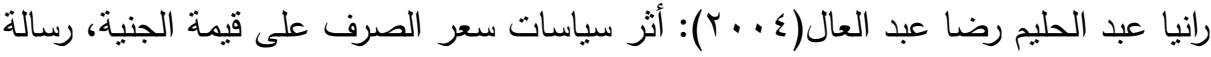
ماجستير ، كلية التجارة، جامعة عين شمس أكس.

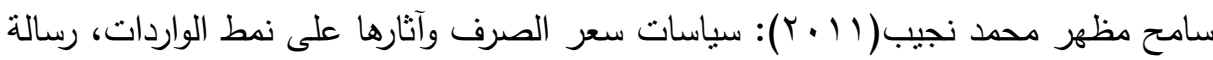
ماجستير، كلية التجارة، جامعة عين شمس.

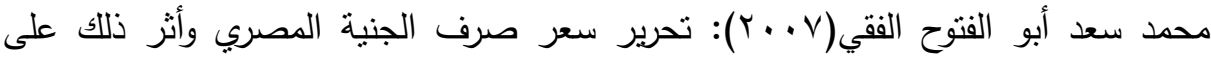

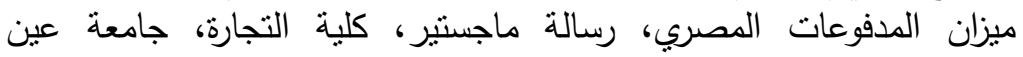
شمس،.

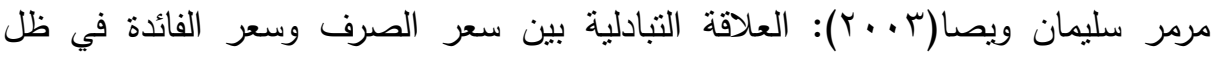
المتغيرات الاقتصادية، رسالة ماجستير ، كلية التجارة، جامعة عين شمس.

Zahra Bakhshi, Mehrzad Ebrahimi. The effect of real exchange rate on unemployment Shiraz Branch, Islamic Azad University, Shiraz, Iran.

البنك المركزي المصري، التقارير السنوية، والمجلة الاقتصادية، أعداد مختلفة. جهاز التعبئة العامة والإحصاء، تقارير مختلفة.

https://ar.m.wikipedia.org

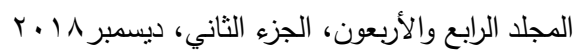


مريم يحيي جاد وآخرون

\title{
STUDY AND ANALYSIS OF THE IMPACT OF EXCHANGE RATE CHANGES \\ ON SUSTAINABLE DEVELOPMENT AND A REFLECTION ON THE SIZE OF UNEMPLOYMENT IN EGYPT
}

\author{
Marim, Y.Gad ${ }^{(1)}$; Ahmed, F. Mandour ${ }^{(2)}$ and Magda, Jibril ${ }^{(2)}$ \\ 1) Institute of Environmental Studies and Research, Ain Shams \\ University 2) Faculty of Commerce, Ain Shams. University
}

\begin{abstract}
Egypt has witnessed a lot of economic decisions in the recent period, which aims at directing and correcting Egypt's economic path in order to achieve sustainable economic development. Hence the importance of the message and its importance in trying to know the impact of changes in the exchange rate on sustainable development and the impact of this impact on the size of unemployment in Egypt in an attempt to eliminate unemployment in Egypt and the preservation of human wealth and development as one of the most important social dimensions of sustainable development, Using the real analytical method using the recent data issued by the Central Bank of Egypt and the general mobilization and statistics system, which resulted in the following.

The changes in the exchange rate have had a positive effect on the size of the monetary reserves after the decision to liberalize the exchange rate. The monetary reserves increased from 21 billion pounds in fiscal year 2016 to 31.3 billion pounds at the end of December 2017. Despite the effect of Seems to be positive, but the source of this increase in the volume of reserves remains the source of remittances of
\end{abstract}


workers abroad and is not due to the increase of the export power of the country.

The positive impact, which seems clear and positive as a result of changes in the exchange rate after the floating decision on the volume of foreign direct investment, but the reflection of this impact on the unemployment rate came negative as the rates of unemployment before the decision to float the exchange rate between $13.3 \%$ in 2013 / 2014 and then became $12.7 \%$ in the fiscal year $2014 / 2015$ to reach $11.9 \%$ in fiscal year 2016/2017, ie after the decision to float, that the unemployment rate is still in the borders of security and accepted globally

Key Words: The Black Market ‘Exchange Rate ‘Sustainable Development 